\title{
Tales from Shakespear no Brasil: traduções \\ e adaptações do conto "The Tempest" endereçadas ao leitor infantojuvenil
}

Marilise Rezende Bertin

\section{Introdução}

É fato que a obra de William Shakespeare se multiplica há quase trezentos anos por meio das inúmeras reescrituras ${ }^{1}$ de suas peças, produzidas nos mais diversos idiomas, entretendo variados tipos de públicos. São muitos os meios de comunicação pelos quais Shakespeare reaparece e se reafirma como um clássico: Internet, cinema, teatro, televisão, música, livros. Shakespeare se faz presente necessariamente em todos os tipos de mídias, nas mais diversas formas.

Entro neste momento ${ }^{2}$ na Internet, digito "William Shakespeare" no site do google e imediatamente aparece o número impressionante de 37.700 .000 resultados em aproximadamente 0,16 segundos. São biografias do bardo, sua obra completa on-line, a análise dela por estudiosos, partes de filmes, dentre outros. O cinema mundial conta com centenas de filmes embasados nas peças de Shakespeare e muitos deles se tornaram famosos. Recentemente, O Mercador de Veneza (2004) contou com uma produção primorosa e um elenco de primeira grandeza. Joseph Fiennes interpretou Bassanio, Jeremy Irons se tornou Antonio, Al Pacino encar-

O termo reescritura, que ficou famoso principalmente ao ser utilizado por André Lefevere, compreende, a meu ver, traduções e adaptações.

2 "[N] este momento" faz parte do dia 23 de junho de 2011. 
nou o judeu Shylock. O filme impressionou o público de tal maneira que "transferiu-se" para a Broadway, sendo "exibido" como peça no "Broadway Theater" em 2010; - uma produção de Daniel Sullivan: Al Pacino interpreta o judeu no teatro após tê-lo feito no cinema.

Aqui no Brasil as telenovelas frequentemente se utilizam de enredos shakespearianos - ou partes deles - na produção de seus textos. Um exemplo entre tantos, é a novela global Sete Pecados, escrita por Walcyr Carrasco et al, exibida pela primeira vez em 2007 e reprisada em 2010. Dentre as personagens importantes, porém não principais, que fazem parte de um dos subenredos da história, temos Juju (a viúva Julieta Verona) interpretada por Nicete Bruno. Na trama, ela reencontra e se apaixona novamente por seu grande amor de juventude Romeu (interpretado por Ary Fontoura). No entanto, o filho de Juju, Teobaldo Verona (interpretado por Roberto Bataglin), um mau caráter, capaz de qualquer atrocidade, proíbe terminantemente o amor dos dois durante a novela inteira, perseguindo Romeu sem cessar. Na peça de Shakespeare, Tybalt (traduzido em português por Tebaldo ou Teobaldo) é o jovem primo da garota Julieta e é aquele que persegue o também jovem Romeu. Na peça de Shakespeare, Tybalt é morto por Romeu no meio da peça, porém na telenovela de Carrasco, Teobaldo e Romeu fazem as pazes no final da novela e tudo acaba bem.

Na música, não posso deixar de citar Angra, grupo brasileiro de heavy metal. Com altas vendagens nos EUA, Europa e Japão, seu novo CD Aqua, lançado em 2010, usa como "conceito" a literatura, mais precisamente a peça $A$ Tempestade de Shakespeare. A unidade também é dada pelos sons, que se iniciam de maneira estrondosa e evoluem juntamente com a peça de Shakespeare, representando a fúria de Próspero, um ser completamente envolvido por sentimentos de mágoa e vingança. Contudo, no decorrer da composição musical, a melodia vai abrandando e cedendo à suavidade, à medida que o coração de Próspero se acalma e acaba por perdoar aqueles que the fizeram mal. As canções, em inglês, contam a história do mágico Próspero em linha cronológica, alinhadas à peça de Shakespeare, e complementam a obra musical de forma perfeita. $O$ rosto de um velho estilizado é a capa do CD. Da cabeça partem relâmpagos, gotas de água, sobre um fundo que é um céu escuro e se misturam com um mar agitado, em plena tempestade. A capa é criação do artista brasileiro Gustavo Sazes, que já fez capas para CDs de outras bandas brasileiras. A música, canções e vídeos estão disponíveis na Internet. 
Os exemplos acima comprovam a multiplicidade de maneiras pelas quais os textos shakespearianos são traduzidos, adaptados ou apropriados e endereçados às mais diversas mídias, nos quatro cantos do mundo. Os públicos são os mais diversos.

Assim também são as recriações dos textos shakespearianos publicados em livros. Pode-se mudar o enredo, alterar as personagens. Não é raro fazer-se uso de cortes e/ou adições. A linguagem pode ser a mesma ou equivalente àquela escrita pelo bardo inglês. Ou então, ao contrário, ela pode ser mais moderna; - com ou sem rimas; neste último caso, sem inversões ou metáforas; mais direta. A mudança de gênero (o texto teatral é reescrito, por exemplo, em texto narrativo, em formato de conto ou novela) é uma adaptação cuja estratégia ${ }^{3}$ primeira visa levar as peças de Shakespeare em outro formato a um público leitor que goste de ler contos, histórias, novelas, romances. Ou que necessite e/ou deseje um texto mais simplificado e de mais fácil entendimento. Ou que queira travar um primeiro contato com a obra de Shakespeare. Crianças, adolescentes e adultos são os leitores-alvo desse tipo de texto.

É sobre reescrituras brasileiras shakespearianas em texto narrativo que este artigo irá tratar, de agora em diante, em maior profundidade. Esses textos derivam, em grande parte, dos Tales from Shakespeare (Contos de Shakespeare) escritos pelos irmãos ingleses Charles e Mary Ann Lamb em 1807. Contudo, para melhor entender o propósito dos irmãos Lamb, ao adaptarem vinte peças de Shakespeare para jovens, em contos, faz-se necessário trazer um pouco de informação sobre a história da literatura infantojuvenil ocidental.

\section{Breve histórico sobre a literatura infantojuvenil}

De acordo com o artigo Children's Literature", "[...] a primeira literatura escrita especificamente para crianças tinha como objetivo instruí-las ${ }^{5}$. Na Idade Média, os Venerandos Bede, Aelfric, St. Aldhelm, e St. Anselm escreveram textos escolares em Latim, os quais foram mais

3 BASTIN, Georges L. BASTIN. Traducir o adaptar. Universidad Central de Venezuela. Consejo de Desarrollo Científico y Humanístico. Caracas: Facultad de Humanidades y Educación, 1998.

4 In: The Columbia Encyclopedia, Sixth Edition. Publisher: Columbia University Press Place of Publication: New York. Publication Year: 2009.

5 Negrito meu. 
tarde utilizados em escolas inglesas e da América colonial." As fábulas de Esopo e A Morte d'Arthur de Sir Thomas Malory foram publicadas respectivamente em 1484 e 1485 por William Caxton. Livros que ensinavam as crianças a ler e a rezar foram também publicados em formato de quadrinhos e chapbooks.

As primeiras "obras" de literaturas juvenis relevantes na Inglaterra e EUA consistiram de histórias tristes e piedosas de crianças mortas e santificadas, escritas para a edificação de crianças puritanas. É desse período o clássico para crianças e adultos $O$ Peregrino de John Bunyan (1678). Mais tarde, apareceram clássicos endereçados a adultos, porém adaptados para crianças. Robinson Crusoé de Daniel Defoe (1719) e As viagens de Gulliver de Jonathan Swift (1726) são os mais importantes.

Em 1729 foi lançada na Inglaterra a tradução dos Contos da Mamãe Gansa de Charles Perrault. Seguiram-se outros contos de fadas, contudo, no final desse século, sob a influência de Locke e Rousseau, a literatura juvenil voltou a tornar-se didática. Esse momento é de produção intelectual e moralística. Martha Finley (pseudônimo de Martha Farquarson), autora da famosa série Elsie Dinsmore, é um exemplo importante.

\section{O movimento romântico e a gênese dos Tales from Shakespear}

O movimento romântico, em pleno século XIX, contrasta e se opõe ao momento anterior moralista. Cito novamente o artigo Children's Literature em que se lê que é na fase romântica que a literatura infantil ganha corpo pela primeira vez. É nessa época que se começa a produzir textos cheios de fantasia e realismo, divertimento e aventura e muitos dos livros escritos nesse século são populares até os dias de hoje.

Os Tales from Shakespear, publicados inicialmente em dois volumes pelos irmãos ingleses Charles e Mary Ann Lamb foram escritos em um momento histórico quando os escritores Românticos do século XVIII colocaram mais ênfase na infância e na criança. ${ }^{6}$ Charles era escritor e ensaísta e partilhava dos ideais do movimento Romântico. Era amigo de poetas famosos como Coleridge, Wordsworth, bem como do crítico Hazlitt

RICHMOND, Velma Bourgeois. Shakespeare as Children's Literature: Edwardian Retellings in Words and Pictures. USA: McFarland, 2004, p. 3. 
$e$ de Godwin, autor de romances e tratados socialistas. As cartas que Charles escreveu aos seus amigos são uma fonte inesgotável de informações sobre a sua vida e os seus ideais românticos; ele acreditava que a leitura deveria ter a função de levar o jovem a sonhar. Tais impressões caminhavam juntamente com um momento de grande ascenção de edição de livros infantojuvenis. Em uma carta endereçada a Coleridge, "durante um período de intensa proximidade entre os dois homens" reflete sobre um período histórico quando o mercado livreiro vislumbrava uma grande oportunidade de lucros certos na publicação de obras infantis, literatura essa que começava a ascender. Charles se incomodava com escritores que escreviam em prosa para crianças enfatizando em seus textos a importância das boas maneiras e de uma moral ilibada, o cultivo de princípios elevados, assim como a abordagem dos fatos da ciência. Contudo, tais escritores, de acordo com a visão dos Lambs, não desenvolviam textos onde se podia sonhar. Ao pensar em escrever contos para crianças, Charles e Mary acreditavam no que Charles chamou de "wild tales" ao escrever a Coleridge:

'Wild tales' are essential reading, the stimulus of a developing imagination, a resource in the tedium of day-to-day existence, sparking lasting pleasure and keeping alive the crucial capacity to daydream. ${ }^{8}$

Na mesma carta, ao mencionar uma visita a uma livraria, Charles comenta sobre os livros infantis escritos por Mrs. Barbauld e Mrs. Trimmer, e demonstra claramente o seu repúdio por um tipo de leitura que nada teria de estimulante para a imaginação juvenil.

Marina Warner, em sua "Introdução" ao livro Tales from Shakespeare, publicado pela Penguin em 2007, chama a atenção para o fato de que apesar dos dois jovens escritores estarem ostensivamente preocupados com crianças, eles não queriam dizer crianças simplesmente: quando Coleridge invoca a imaginação de uma criança, ele anseia tal poder para ele mesmo. Segundo a ode de Wordsworth, "Intimations of Immortality", a criança poderia ser "o pai do homem". Essa paternidade seria ideal se

WARNER, Marina. "Introduction". In: LAMB, Charles \& Mary. Tales from Shakespear. England: Penguin Classics, 2007.

8 Carta de Charles Lamb para Samuel Taylor Coleridge, de 23 de outubro de 1802, citada em The Works of Charles and Mary Lamb, vol. III, Books for Children, (ed.) E. V. Lucas. London: Methuen, 1903, pp. 474-5. 
fosse interna, presente e ativa. Os românticos foram os primeiros a conceber o conceito da "Inner Child" e desejar que a criança dentro do homem perdurasse e dominasse 0 adulto. ${ }^{9}$ Os Românticos acreditavam na criatividade e quando os Lambs, no Prefácio de seus contos, "... exhort his readers to enrich fancy and strengthen virtue and discover generosity and humanity", eles estavam escrevendo de si para si, criando o texto shakespeariano segundo a sua imaginação, e, dessa forma, provando o princípio romântico de que o olho interno pode, segundo Warner, trazer um tipo de alegria sequestrada, senão de beatitude e de bem-aventurança. Eles reescreveram, portanto, os contos de um Shakespeare idealizado por eles; contos esses que não eram, necessariamente, iguais às famosas peças teatrais, mas que talvez possam ter sido aqueles com quem milhares de leitores - crianças, jovens ou adultos -, se identificaram.

Os Tales from Shakespear têm vinte contos. A base são vinte peças do bardo inglês a saber 10: "The Tempest", "A Midsummer Night's Dream", "The Winter's Tale", "Much Ado About Nothing", "As You Like It", "The Two Gentlemen of Verona", "The Merchant of Venice", "Cymbeline", "King Lear", "Macbeth", "All's Well that Ends Well", "The Taming of the Shrew", "The Comedy of Errors", "Measure for Measure", "Twelfth Night, or What You Will", "Timon of Athens", "Romeo and Juliet", "Hamlet, Prince of Denmark", "Othello" e "Pericles, Prince of Tyre".

Charles adaptou as seis tragédias "King Lear", "Macbeth", "Hamlet, Prince of Denmark", "Othello", "Romeo and Juliet", "Timon of Athens", e sua irmã, Mary, ficou com a responsabilidade de adaptar os quatorze contos restantes, que derivam de comédias shakespearianas. Tal afirmação consta em uma carta escrita por Charles Lamb a William Wordsworth: 'I am answerable for Lear, Macbeth, Timon, Romeo, Hamlet, Othello, for occasionally a tail piece or correction of grammar, for more of the cuts and all the spelling. The rest is my Sister's. ${ }^{11}$

9 William Wordsworth, "Intimations of Immortality from Recollections of Early Childhood", apareceu em seus Poems in Two Volumes (1807).

10 Os seguintes contos, na ordem em que aparecem nos Contos de Shakespeare, são: "A Tempestade", "Sonho de Uma Noite de verão", "Conto de Inverno", "Muito Barulho por Nada", "Como Gostais", "Os Dois Cavalheiros de Verona", "O Mercador de Veneza", "Cimbeline", "O Rei Lear", "Macbeth", "Bem está o que Bem Termina", "A Megera Domada", "A Comédia dos Erros", "Olho por Olho", "Noite de Reis", "Timon de Atenas", "Romeu e Julieta", "Hamlet, o Príncipe da Dinamarca", "Otelo", "Péricles, príncipe de Tiro".

11 LAMB, Charles \& Mary. The Letters of Charles and Mary Lamb, E. V. Lucas, ed., vol. 6 The Works of Charles and Mary Lamb (London: Methuen, 1903-5) Letter no. 152 (June 26 1806). 
William Godwin, amigo dos Lambs, foi o editor audacioso que vislumbrou a possibilidade de obter grandes lucros ao publicar adaptações do cânone da língua inglesa para o mercado infantojuvenil que despontava na Inglaterra. Godwin acertou, porque os contos foram um imenso sucesso. Muitas crianças foram apresentadas ao bardo inglês por meio da versão dos Lambs. Os "pais-sensores"12 desses alunos leram os contos também. A coletânea Tales from Shakespear atravessou mares e aportou em muitos países ${ }^{13}$, difundida por meio de traduções e adaptações. ${ }^{14}$ Chegou ao Brasil no início do século XX, por volta de 1920. E compõe o quadro dos clássicos adaptados da literatura infantojuvenil até os dias de hoje.

A grande maioria dos primeiros e principais textos brasileiros são traduções. Até a década de 1960 eles eram endereçados a um público mais geral, não o infantojuvenil especificamente. A ideia escondida por detrás dessa atitude fica clara. Introduzir um bom número de peças shakespearianas de uma maneira rápida e fácil, trazendo o enredo básico presente nos contos dos irmãos Lambs. Logo, todos os vinte contos dos Lambs foram traduzidos e publicados em um ou dois volumes. A partir da década de 1970, com o advento de uma política educacional mais ampliada, muitos desses contos passam a ser publicados em menor número, em um ou dois volumes (ou até em um único livro, neste caso, geralmente ricamente ilustrado), e têm como alvo o leitor infantojuvenil principalmente. As adaptações também aparecem: publicam-se condensações dos contos, ou, ao con-

12 Ao fazer uso do termo "pai-sensores" refiro-me a uma grande parcela de genitores que lêem, antes de seus filhos, textos endereçados aos jovens e repudiam qualquer material escrito que aborde assuntos "proibidos" para os pequenos. Violência e sexo são exemplos dos temas expurgados.

13 Doris Jedamiski ["Translation in the Malay World". In: Asian Translation Traditions, (eds.) Eva Hung e Judy Wakabayashi. Manchester: St. Jerome Publishing, p. 233] coloca a importância dos textos dos Lambs na formação da literatura em Malay, em princípios do século XX. Diz a autora que de acordo com Tzu You (1939:23), "... all ... the Shakespeare's plays had lost their theatrical form and undergone a transformation into 'normal prose'. Such Malay prose-versions were commonly based (itálico meu) on Charles Lamb's Tales from Shakespeare".

14 Em artigo intitulado "Universals in Translation: a Look at the Asian Tradition". (In: Tradução e comunicação. Revista brasileira de tradutores, $n^{\circ} 17$, pp. 95 - 103, 2008), John Milton, baseado nas recentes publicações sobre a tradução na Ásia, em especial os três volumes lançados pela St. Jerome, 'Asian Translation Traditions', organizados por Eva Hung e Judy Wakabayshi, e os dois volumes 'Translating Others', organizados por Theo Hermans, afirma que "Simplified versions of Shakespeare's plays were available in many countries, particularly translations of the Lambs Tales from Shakespeare, which, for example, was available in Japan in 1907 and at least made the basic plots of Shakespeare familiar to many (Gallimore in ed. Hermans, 2006, vol. 2: 485)". 
trário, ampliações dos mesmos. Tais ampliações muitas vezes têm como dupla fonte os contos dos Lambs e as peças de Shakespeare. Publicadas em um único livro, compõem as novelas endereçadas ao leitor mirim.

Trazer em cena um pouco dessa grande variedade de textos e analisála significa ampliar os horizontes e analisar os "múltiplos Shakespeares" que convivem neste grande país. Tendo em mente o grande número de contos e as várias traduções, adaptações e versões brasileiras, para este artigo decidiu-se restringir o corpus para apenas um excerto de um conto, 'The Tempest'. Este excerto é composto dos dois primeiros parágrafos.

A maneira escolhida para apresentar tal trabalho foi agrupar em colunas o excerto em inglês, seguido pelas seis principais traduções (uma delas, o segundo trecho de Mario Quintana, é uma atualização), e por três adaptações brasileiras, cujos textos são equivalentes aos referidos parágrafos. Na sequência, transcrevo o início de outra adaptação, uma novela publicada pela Scipione, e baseada, conforme divulgado, no texto de Shakespeare e não no dos Lambs. 


\begin{tabular}{|c|c|c|}
\hline 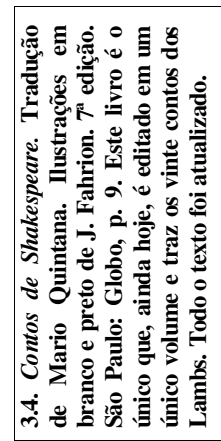 &  & \\
\hline  & 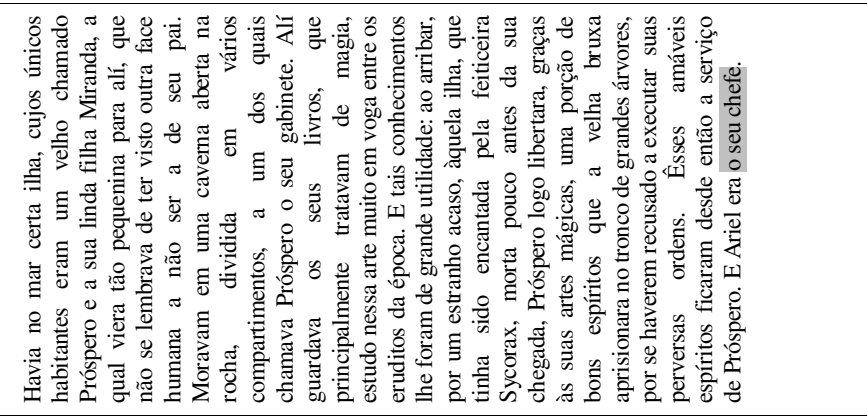 & \\
\hline 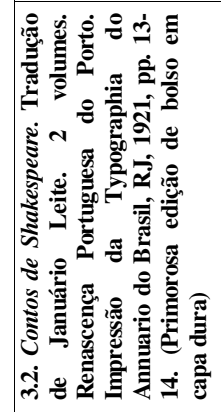 &  & \\
\hline 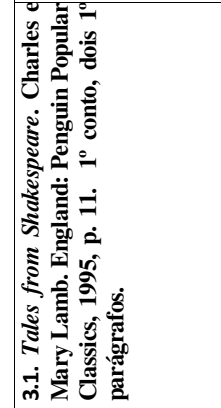 & 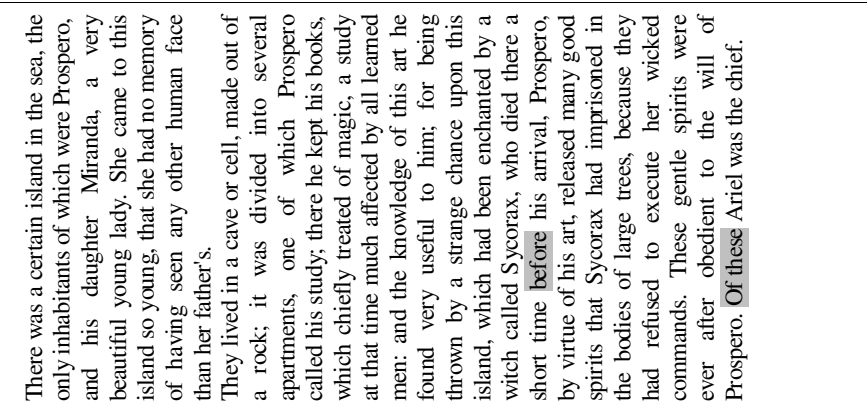 & \\
\hline
\end{tabular}




\begin{tabular}{|c|c|c|}
\hline 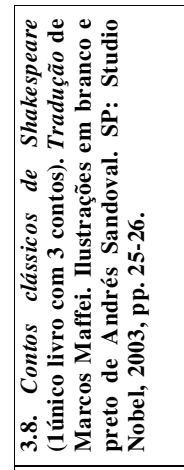 & 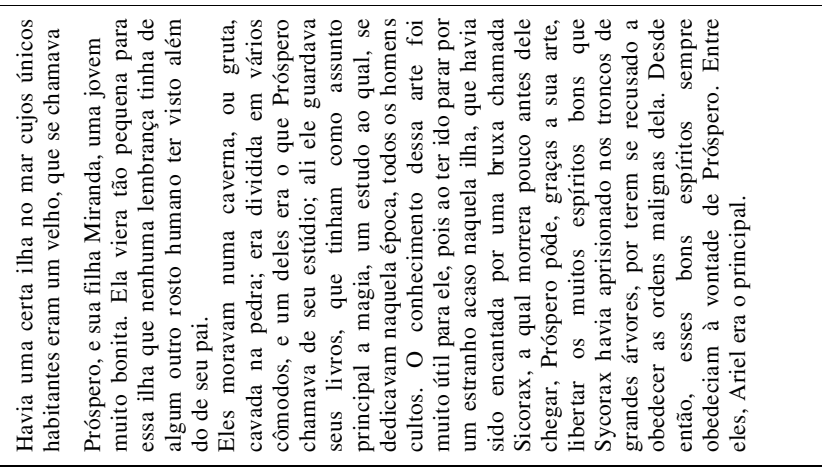 & \\
\hline 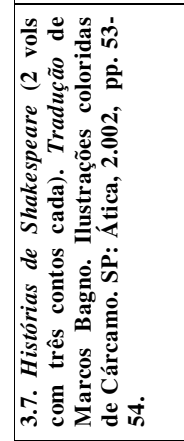 & 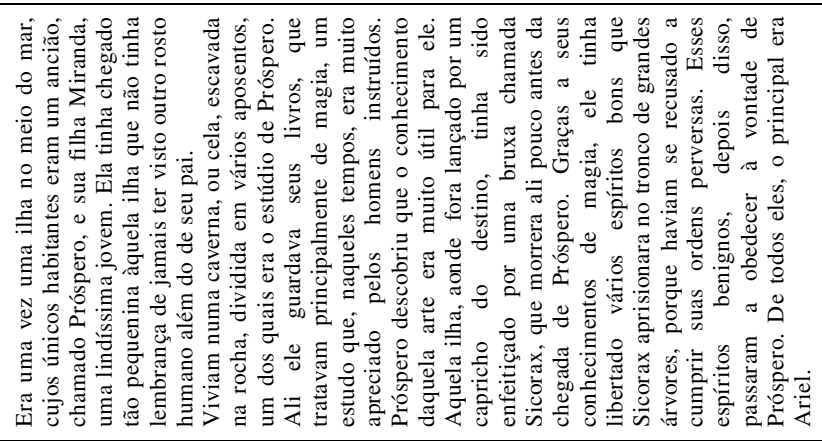 & \\
\hline 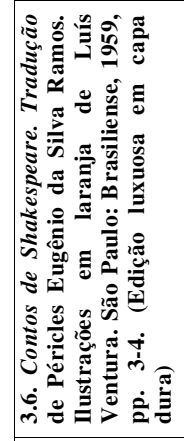 & 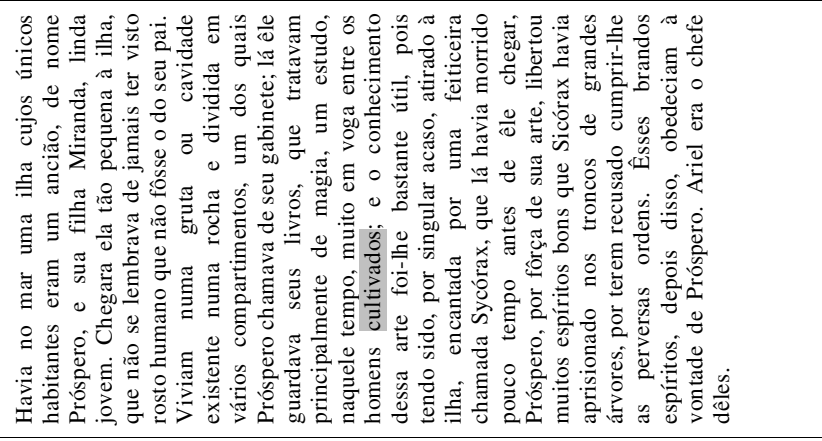 & \\
\hline 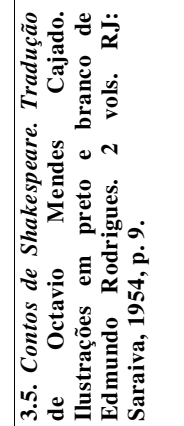 & 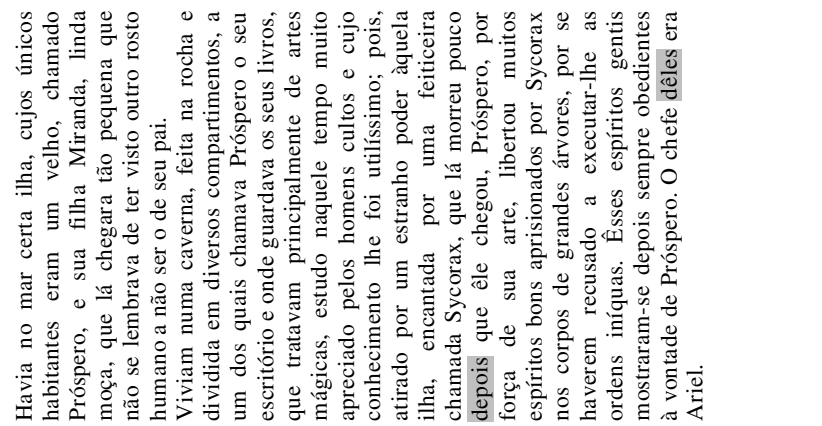 & \\
\hline
\end{tabular}




\begin{tabular}{|c|c|c|}
\hline 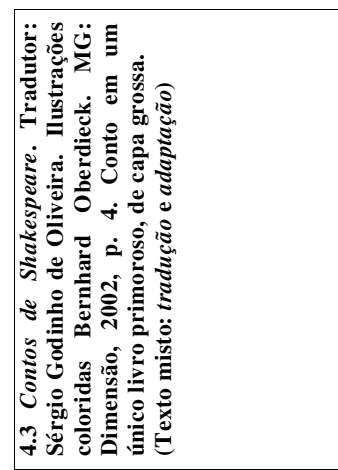 & 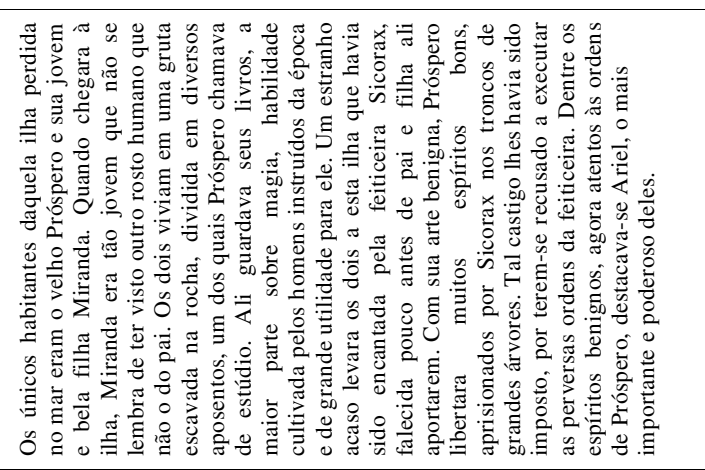 & \\
\hline 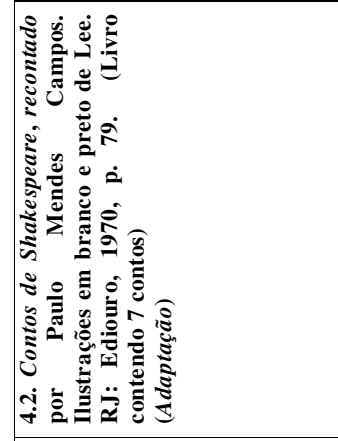 & 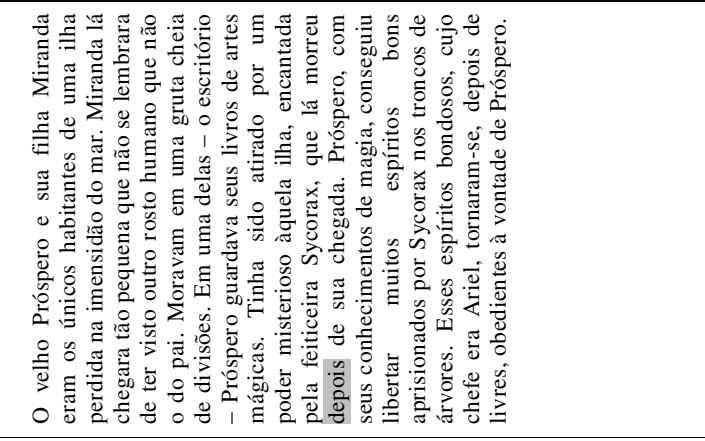 & 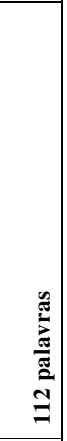 \\
\hline 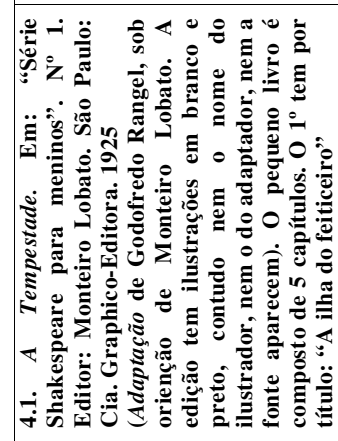 & 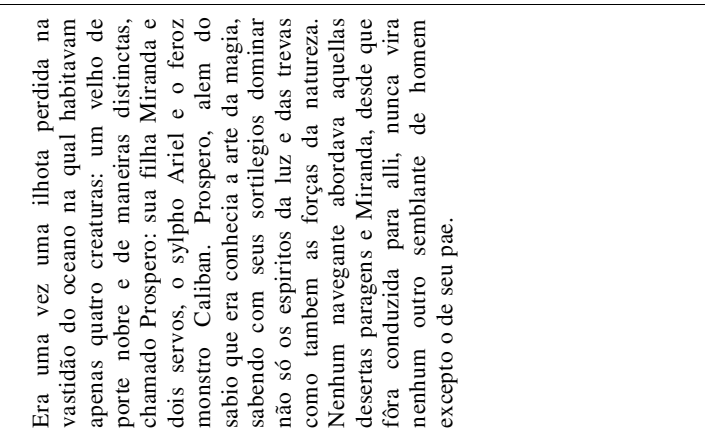 &  \\
\hline 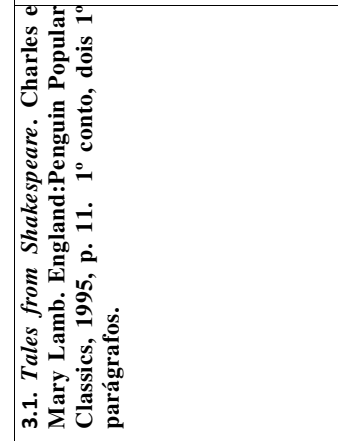 & 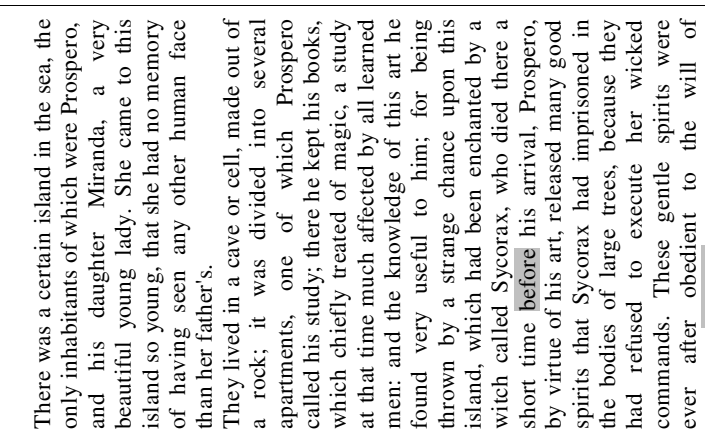 & \\
\hline
\end{tabular}


A tempestade, de William Shakespeare

Adaptação de Sonia Rodrigues

Ilustrações em preto e branco de Cecília Iwashita

Série REENCONTRO Literatura

SP: Editora Scipione, 2002, pp. 5-7

\section{CAPÍTULO I}

\section{$O$ mar}

Em algum lugar do imenso oceano, num ponto perdido entre a cidade de Túnis, na África, e o reino de Nápoles, no Mediterrâneo, um navio se debatia contra uma terrível tormenta, em meio a incessantes trovões e relâmpagos. $O$ capitão, homem experiente como convém a um comandante que conduz um rei e sua comitiva em seu navio, conclamava o contramestre e os marinheiros para lutar contra o mar bravio. As ordens de baixar velas na popa e depois alinhá-las e aparelhá-las para alto-mar eram gritadas para os marujos, encharcados pelas ondas que se abatiam sobre o navio, tornando o convés cada vez mais escorregadio. Os marinheiros eram rápidos em cumprir as ordens do capitão, na esperança de escapar da pavorosa tempestade.

Navegar pelo oceano é quase sempre uma grande aventura, muitas vezes cheia de realizações e descobertas importantes. Mas é também um risco incalculável: por maior que seja a competência dos capitães, os marujos sabem que o mar é ao mesmo tempo um espaço a ser conquistado e um lugar cheio de perigos. Muitas são as lendas e os relatos terríveis sobre os naufrágios: frotas bem equipadas, tripulações inteiras, sonhos de riquezas colhidas em terras distantes tragados pelo mar implacável em noites de tempestade como aquela.

Não fazia muito tempo, uma frota inglesa naufragara em algum ponto entre a Europa e o Novo Mundo. Uns poucos tripulantes conseguiram chegar até uma ilha selvagem que chamaram de Ilha do Diabo e lá permaneceram entre os nativos por dez longos meses. A história desse naufrágio correra os portos da Europa, aumentando ainda mais o fascínio que o mar exercia sobre as pessoas, mas também o medo. Medo de ser engolido pelas ondas gigantescas como se o navio fosse uma frágil casca de noz. 
Medo de sobreviver à tempestade, mas morrer antes de alcançar terra firme. Medo de ver-se preso em uma ilha habitada.

Existiam ainda histórias sobre monstros marinhos, sereias, espíritos maléficos e toda a sorte de perigos a rondar os que faziam do mar seu trabalho e seu destino.

Apesar de ter lutado contra a tempestade por toda a noite enquanto os nobres da comitiva rezavam apavorados em seus camarotes ou atrapalhavam com suas perguntas o esforço de salvamento, chegou um momento em que a tripulação se reconheceu derrotada. Uns bebiam, certos de ser o último trago; outros, desesperados, gritavam pela família que deixaram em terra distante. Alguns choravam e rezavam.

Gonçalo, o velho conselheiro de Alonso, rei de Nápoles, ao ver que estava tudo perdido, pensou, antes de se dirigir ao camarote de seu senhor:

- "Daria, com prazer, milhares de braças de mar por um pedaço de terra, terra seca, com espinhos, com urtigas, terra sem nada. Que se cumpra a vontade de Deus, mas eu preferia morrer uma morte seca!"

\section{Comentário sobre os excertos das traduções}

O poeta lírico cabo-verdiano António Januário Leite nasceu em Santo Antão, Cabo Verde, em 10 de junho de 1867, e faleceu em 1930. Pouco se sabe sobre sua vida, uma vez que foi, até bem pouco tempo, considerado um poeta menor. Todavia, diz-se que Leite era um homem de "vida pobre, algo apagada, um triste com a obsessão da morte" ${ }^{15}$. Escreveu sonetos e outros poemas de métrica variada e assinava também como A. Corsino Lopes, quando, por exemplo, escreveu o texto "Cabo Verde aspira ao que merece", presente em Cabo Verde: órgão republicano defensor dos interesses do Arquipélago. - Ano 1, $n^{\circ}$ XIV, (1920), p. 3. Comenta-se que fez algumas traduções e os Contos de Shakespear figura entre elas.

15 Informação encontrada no dia 30 de junho de 2011, no site http://saial.info/index.php? option=com_content\&task=view\&id=153\&Itemid=37 
O trecho traduzido por Leite é fiel ao texto de Mary Lamb. Na maior parte das vezes, o tradutor preocupa-se em produzir equivalentes para cada palavra e frase de tal forma que o texto final é uma "cópia" quase perfeita do texto inicial. Mesmo quando faz pequenas alterações, em raros momentos, Leite o faz com o intuito de explicar o sentido do original, aproximando o texto inglês ao leitor português. Exemplifico citando a palavra inglesa "studio", provavelmente desconhecida da língua portuguesa da época, que é substituída por "gabinete de trabalho".

Nesse excerto, Leite também traz informações adicionais acerca das personagens, com o intuito de auxiliar o leitor a criar uma imagem mais nítida delas. Por exemplo, ao fazer uso da palavra velho, quando se refere a Próspero, Leite associa a imagem do mágico a alguém de idade avançada. Em momento algum, durante todo o conto de Mary Lamb, menciona-se algo sobre a idade de Próspero, o que faz crer que Leite deveria conhecer a peça de Shakespeare, onde em alguns momentos é sugerido que Próspero poderá morrer em breve. (Ex.: 'Every third thought shall be my grave'. A to 5, cena 1). Uma das interpretações possiveis do texto shakespeariano poderia associar a morte à idade longa, o que justifica, de certo modo, a inclusão do termo "velho". Porém se considerarmos os padrões renascentistas, quando se vivia muito pouco, ou mesmo no início do século $X X$, quando as condições de vida ainda eram precárias, a palavra "velho" faria mais sentido. Shakespeare coloca Próspero como alguém beirando os quarenta e cinco anos (quando ele entrega sua filha Miranda, de aproximadamente quinze anos, ao jovem Ferdinando, diz: 'Have given here a third of mine own life' Ato 4, cena 1). Quarenta e cinco anos não é sinônimo de idade avançada hoje em dia, apesar de concordar que um jovem que lesse - livro e soubesse da idade acharia quarenta e cinco anos uma idade de velho. Contudo, esse é um ponto importante a se considerar, visto que todas as traduções e adaptações brasileiras que se seguiram à de Leite, adotam o termo "velho" até hoje.

No texto de Leite, umas poucas palavras como "tam" e "predilecção" apontam para o português de Portugal, porém não apresentariam dificuldades de compreensão ao leitor brasileiro de hoje. Grosso modo, pode-se dizer que a passagem é bem traduzida e fiel ao inglês. Note-se que as demais traduções a serem analisadas seguem a de Januário Leite quase que completamente e ousam pouco em um texto simples e conciso, que não oferece muitos problemas tradutórios, que se aproxima muito do texto de Mary em tamanho. 
O escritor brasileiro Mário Quintana (1906 - 1994) escreveu um grande número de obras poéticas, livros infantis, antologias. Fez um número sem fim de traduções de escritores franceses, ingleses e italianos, sempre para a editora Globo. Era um aficcionado por Shakespeare.

A sua tradução de 'The Tempest' não difere muito daquela traduzida por Leite, apesar de Quintana evitar grafia portuguesa, fazer uso de vocabulário brasileiro mais moderno (ex.: "linda" em vez de "formosa"; "rosto" em vez de "face" - no texto atualizado -, "tratavam" em vez de "versavam", "morta" em vez de "falecida", "grandes" em vez de "corpulentas"). Quintana escreve um texto mais seco, condensado - é a menor tradução dentre todas - ("gabinete de trabalho de Próspero" passa a ser apenas "gabinete", "por uma feiticeira" passa a ser "pela feiticeira"), entretanto se mantém fiel em língua e significado ao texto dos Lambs (ou ao texto de Leite). O texto "atualizado" de Quintana traz poucas alterações: uma delas ocorre na acentuação (ex.: "êsses" passa a ser "esses"), e há a supressão de umas poucas vírgulas e da palavra "chamada". O termo "arribar", que significa "acolher um navio ou barco a um porto por causa de uma tempestade ou vendaval", traz um sentido diverso e mais completo do que o texto dos Lambs ('[...] being thrown by a strange chance upon this island [...]"), que utiliza "sendo atirado", à imagem de mares que "rugem" enquanto pai e filha e alguns pertences estão sós em um barco sem remos ou mastro em pleno mar.

Octavio Mendes Cajado, tradutor por profissão, traduziu as grandes obras clássicas francesas e inglesas. Nesse específico excerto de os Contos de Shakespeare, Cajado mantém sua tradução muito próxima das anteriores, apesar de ser um pouco menor e simplificar e resumir frases como "de grande utilidade" por "utilíssimo", por exemplo. No entanto, comete o grave erro ao traduzir "[...] Sycorax, who died there a short time before his arrival [...]' por "[...] Sycorax, que lá morreu pouco depois que êle chegou $[\ldots]^{\prime \prime}$.

Péricles Eugênio da Silva Ramos (1919 - 1992) foi poeta, tradutor, ensaísta, crítico literário e professor brasileiro. A tradução de seu texto é mais bem elaborada $e$, consequentemente, um pouco mais longa, se comparada à de Cajado, mas está longe de ser a mais longa de todas.

Nascido em Cataguases, Minas Gerais, Marcos Bagno é escritor, tradutor, linguista e professor da UnB. Sua tradução, mais moderna, exceto por começar o texto com o famoso "Era uma vez uma ilha no meio do mar" (a expressão "era uma vez..." é sabidamente muito utilizada em 
textos para crianças), mantém o tom infantojuvenil ao traduzir "very beautiful" por "lindíssima". Bagno também opta por traduzir "in the sea" por "no meio do mar", o que, na minha concepção, traz um tom infantil ao texto. No geral, a tradução de Bagno é pertinente ao original e às outras traduções.

Assim é a tradução de Marcos Maffei, que é tão recente (2003) quanto a de Bagno (2002) - longa e bem elaborada, muito próxima em número de palavras à adaptação de Mary Lamb -, ou à tradução/adaptação de Sérgio Godinho de Oliveira (2002). As três reescrituras são as únicas a utilizar o termo "estúdio" como adaptação de 'study', palavra essa incorporada à língua portuguesa. A tradução de Maffei tem vocabulário facilitado, por vezes, endereçado aos pequenos (Miranda era "uma jovem muito bonita"). O texto é muito bem escrito e se aproxima muito do de Mary. A linguagem é atual, proporcionando uma leitura agradável e é bem longo, contendo o mesmo número de palavras da adaptação escrita por Mary Lamb.

Dedico algumas palavras ao texto de Oliveira, endereçado a crianças. Um pouco conciso, com o olhar no público infantil, este texto faz uso das duas técnicas: a tradução (ao ser fiel ao texto fonte) e a adaptação. Esta segunda estratégia não é observada nos dois primeiros parágrafos, uma vez que eles seguem bem de perto o texto de Lamb. Ela aparece no decorrer do texto, no formato dos parágrafos, que diferem totalmente daqueles escritos por Lamb. Com a evidente preocupação de tornar a leitura mais acessível aos leitores-mirins, Oliveira divide os parágrafos do texto de Lamb em um número bem maior de parágrafos menores com o óbvio intuito de facilitar a leitura aos pequenos.

Importa ressaltar ainda que a tradução da editora Globo, feita por Quintana, é a única que é impressa nos dias de hoje, uma vez que a de Cajado e Ramos tiveram impressões só até fins dos anos 1960. A tradução de Quintana convive com traduções mais recentes como as editadas pela Ática, Studio Nobel e Dimensão.

\section{Comentário sobre a adaptação de Paulo Mendes Campos}

A adaptação do jornalista, escritor e tradutor Paulo Mendes Campos (1922 - 1991), a primeira de importância a aparecer em 1970, é muito facilitada e resumida. Telegráfica. $O$ principal é dito em blocos resumidos, em três parágrafos. As frases curtas são direcionadas ao leitor jo- 
vem por excelência. A fonte de Mendes pode ter sido a tradução de Cajado, pois ele comete o mesmo erro ao escrever que Sycorax morrera "depois" da chegada de Próspero à ilha, quando, na verdade, ela morrera "antes". Logo, Mendes talvez não tenha feito uso do texto original em inglês escrito por Mary Lamb. Importa dizer que tal atitude não é incomum no meio editorial. Um tradutor não raro consulta traduções já existentes ao produzir as próprias, especialmente quando está pressionado por muito trabalho e/ou tempo curto.

Na capa dessa adaptação - que é impressa até os dias de hoje -, aparece o termo recontado pelo escritor Paulo Mendes Campos. Importante notar que o termo recontado foi utilizado pela própria editora, Ediouro, antiga Tecnoprint, com sede no Rio de Janeiro; esse livro fazia parte da coleção Edijovem. O termo recontado foi alterado posteriormente. A "nova" publicação de 2006 da Ediouro ( $8^{a}$ edição) traz no topo, no lado esquerdo da capa, os dizeres: Adaptação (itálico meu) de Paulo Mendes Campos. No verso da folha de rosto temos os dizeres: Adaptação de: Tales of Shakespeare! ${ }^{16}$ Os contos adaptados, presentes no pequeno livro, são "Romeu e Julieta", "Hamlet", "Macbeth", "Sonho de uma noite de verão", "Otelo", "A fúria domada" e "A tempestade". Esta adaptação difere das traduções anteriores por motivos óbvios. Com menor número de contos, que são simplificados, é dirigida especificamente ao público juvenil. Todavia, assusta o número de erros que esse livreto encerra.

Os procedimentos principais empregados na adaptação de Mendes são a condensação e a reorganização de páragrafos, porém a ordem do enredo do texto de Mary Lamb é seguida. Já as próximas duas adaptações a serem analisadas, a de Rangel e a de Rodrigues, fazem mais do que isso: elas mudam a ordem do enredo, uma vez que os fatos aparecem em uma ordem diversa daquela organizada por Mary Lamb, que difere daquela escrita por Shakespeare.

\section{Comentário sobre o excerto da adaptação escrita por Godo- fredo Rangel e supervisionada por Monteiro Lobato}

A adaptação escrita pelo escritor e tradutor Godofredo Rangel (1884-1951) faria parte de uma série de livros que seriam publicados pela editora de Monteiro Lobato. Há menção sobre esta adaptação, $A$ tempes-

16 Note-se o erro: o título original é Tales from Shakespeare e não Tales of Shakespeare. 
tade, e a adaptação de Rei Lear no livro A Barca de Gleyre. Quarenta anos de correspondência literária entre Monteiro Lobato e Godofredo Rangel. (São Paulo: Companhia Editora Nacional, 1944, p. 453). Nas cartas que Lobato troca com Rangel ele fala de seu interesse em publicar uma série de contos clássicos adaptados para meninos. A tempestade seria o primeiro, visto que Lobato era apaixonado por Shakespeare, em especial pela peça A tempestade. A fonte que foi utilizada como base para a adaptação de Rangel não apareceu no livro, assim como não apareceu o nome do tradutor/ adaptador Godofredo Rangel. Todavia, em A Barca de Gleyre, Lobato escreve a Rangel dizendo: "os contos extraídos das peças de Shakespeare vão para que escolhas alguns dos mais interessantes e os traduzas em linguagem bem singela". Lobato poderia estar se referindo aos contos dos Lambs.

Apenas A tempestade foi publicada. A Cia. Graphico-editora estava à beira da falência e realmente faliu logo depois. Lobato supervisionou a adaptação de Rangel. Em carta a ele, em 30/08/1924, Lobato escreve: "[...] Breve te mandarei provas da Tempestade, com as emendas que fiz tendentes a puerizá-lo um pouco mais. Os leitores vão ser crianças. Teu estilo estava muito 'gente grande'."

Analisemos, a seguir, o excerto da adaptação de Rangel. Ele se afasta radicalmente do texto dos Lambs, apesar do forte indício de que Rangel/ Lobato se basearam nele.

Logo na primeira frase, a palavra "vastidão" se casa perfeitamente com o "era uma vez" $e$ "ilhota perdida". Tais palavras e frase são típicas de quem conta/narra uma história, principalmente a leitores-mirins, bem pequenos. Elas imprimem um sentido mágico de distância física e atemporal, o que suscita mistério, fantasia e sonho. Conta-se de maneira diferente, de acordo com o leitor. A criança de até onze ou doze anos necessita de um estilo mais leve e mágico, ao passo que o adolescente se interessa por mais aventura, requer mais movimento.

Por conseguinte, é verdadeiro afirmar que a adaptação de Rangel/ Lobato se dirige ao público infantil. Quando na produção de uma nova Tempestade, o narrador Rangel altera o enredo escrito por Mary Lamb e produz o seu, ao optar por introduzir, já no primeiro parágrafo, o espírito Ariel e o monstro Caliban. Nenhuma informação sobre a bruxa Sycorax aparece nesses dois parágrafos. De maneira muito rápida e resumida, 0 segundo parágrafo já traz informações sobre a ilha deserta, e o fato de Miranda desconhecer outro rosto masculino que não seja o de seu pai e do horrendo monstro Caliban. $O$ texto continua falando sobre a vida de Miranda 
naquela ilha até o dia de uma violenta tempestade, onde se avistava um navio no oceano passando por grandes dificuldades. Miranda, preocupada, é tranquilizada por seu pai Próspero, que afirma que tudo está sobre controle e começa a lhe contar como os dois vieram parar nessa ilha. Isso acontece nos próximos cinco pequenos parágrafos.

Já o conto dos Lambs desenvolve, nos seguintes três longos parágrafos, a história de Ariel e Caliban para introduzir a tempestade somente no final do $3^{\circ}$ parágrafo. Sabedores de que, via de regra, por questões das diferenças das duas línguas - a inglesa e a portuguesa -, os parágrafos ingleses são maiores do que os brasileiros, a alteração na "ordem" dos fatos - uma vez que Rangel não segue o modus operandi de Mary Lamb faz com que o texto de Rangel tenha mais liberdade e, consequentemente, se distancie daquele escrito pelos Lambs.

\section{Comentário sobre $01^{\circ}$ capítulo da adaptação de Sonia Rodri- gues da série Reencontro Literatura}

A editora paulistana Scipione publicou um relevante número de títulos de William Shakespeare. A série Reencontro é destinada a adolescentes e traz textos divididos em capítulos e com títulos. Até o momento, foram dez os textos lançados. São eles: "Sonho de uma noite de verão", "Otelo", "Muito barulho por nada", "Romeu e Julieta", "Hamlet", "A megera domada", "Macbeth", "Rei Lear", "A tempestade", "O mercador de Veneza".

Apesar de o texto ser narrativo, a exemplo daquele escrito pelos Lambs, as adaptações da Scipione são maiores do que os contos; elas tem maior produção de texto. São chamadas de novelas, uma forma de texto intermediária entre os contos (dos Lambs, por exemplo), e romances. Ao analisar as muitas reescrituras shakespearianas produzidas no mercado para jovens, nota-se uma preferência em indicar traduções e/ou adaptações dos contos dos Lambs para crianças, ao passo que as novelas são indicadas para jovens de até quinze anos.

Uma rápida leitura do texto de Sonia Maria Rodrigues (PhD em literatura pela PUCRJ e escritora), cuja fonte é a peça de Shakespeare, dá para observar que o enredo da novela apresenta uma ordenação de fatos e situações semelhante ao texto teatral do bardo inglês, o qual difere daquele contado por Mary Lamb. O texto teatral (script) shakespeariano começa com a tempestade vista de dentro do navio: os tripulantes lutam para evitar o iminente naufrágio, ao passo que o texto dos Lambs se 
inicia falando da ilha, de seus novos habitantes (Próspero e Miranda), do local onde habitavam antes de irem parar naquela ilha, da magia que Próspero praticava, da bruxa malvada Sycorax, dos espíritos bondosos, em especial Ariel, a quem Próspero comandava, do monstro Caliban.

A novela de Rodrigues começa narrando o naufrágio e ao fazê-lo traz informações histórico-geográficas sobre a região onde a ilha possivelmente se localizava, bem como sobre naufrágios famosos ocorridos na época de Shakespeare. Discorre sobre perigos, espíritos maléficos; um oceano imenso e hostil. É a partir desse momento que ela começa a narrar a tempestade, o naufrágio prestes a acontecer e a preocupação de Alonso, personagem da peça, com sua vida, prestes a findar. O capítulo seguinte trará Própero explicando à Miranda o motivo daquela tempestade e do naufrágio. Com o decorrer da trama, diálogos passam a ser mais frequentes, contudo parágrafos narrativos, com o intuito de resumir cenas e situações não tão centrais na trama, aparecem com frequência e mesclamse com diálogos.

\section{Conclusão}

Este artigo teve como objetivo fazer um recorte histórico de traduções e adaptações brasileiras dos contos de Shakespeare escritos pelos irmãos Lamb. Os excertos escolhidos foram os dois parágrafos iniciais do conto "A tempestade".

Quando analisando traduções, percebeu-se uma unidade entre as traduções como um todo, assim como entre cada uma delas em relação ao texto de Mary Lamb, apesar de ficar claro, pelo número de palavras de cada excerto, que alguns textos são mais resumidos do que os outros. Entretanto, tais textos não entram na lista daqueles categorizados como adaptações, uma vez que são fiéis ao texto inicial, aquele escrito pelos Lambs, visto que as estruturas linguísticas e semânticas estão preservadas, apesar de, por vezes, possuirem um corpo mais lacônico, mais seco, mais direto ao ponto. As mudanças maiores são sempre pontuais, como o caso da adição do vocábulo "velho". O maior erro notado foi encontrado em dois textos, no de Cajado e no de Mendes, ao mencionar que a bruxa Sicorax morrera depois da chegada de Próspero, quando, na verdade, tal fato acontecera antes.

Já as adaptações são mais ousadas e livres. Condensam, como no caso do texto de Mendes, alteram a ordem dos fatos e o formato do texto 
ao nomearem capítulos e caminharem, dessa forma, para novelas - como é o caso da adaptação de Rangel. E este é um exemplo interessante de como Lobato era um visionário ao orientar Rangel que escrevesse daquela maneira. Apesar de Rangel/Lobato se preocuparem com a fidelidade ao conteúdo do texto de Shakespeare/Lambs, com a ação e com o enredo da história, eles alteraram a ordem e apostaram no estilo novela que se tornou uma forte tendência brasileira, a partir da década de oitenta, visto que foi utilizada por duas grandes editoras nacionais. A editora Scipione é a que mais reescreveu novelas embasadas em Shakespeare, seguida da Escala educacional. Essas editoras contam com alta vendagem nacional de seus títulos o que nos leva a afirmar que muitos jovens brasileiros lêem tais livros. Endereçada especificamente ao jovem leitor, "A tempestade" adaptada por Rodrigues é um bom exemplo. Publicada em 2002, em 2008 já estava na $3^{a}$ edição e na $7^{a}$ impressão.

Quais os tipos de textos narrativos shakespearianos que imperam e continuam a ser editados, a partir da década de setenta, no cenário infantojuvenil? Consideremos que temos a tradução de vintes contos, elaborada por Quintana, que são dirigidos a um público-leitor mais geral, não somente ao público infantojuvenil. Temos, em número reduzido, a tradução de Bagno (em dois livrinhos, com três títulos em cada) e a de Maffei (com três títulos) que se dirigem aos jovens.

Elas estão no mercado juntamente com a adaptação de Mendes (contendo 7 títulos), a tradução/adaptação da editora Dimensão (doze títulos endereçados ao público infantil), as adaptações da Scipione (dez títulos juvenis, quatro infantis) e as adaptações da Escala educacional (dois títulos infantis, seis títulos juvenis); de onde se conclui que as adaptações, em número de seis (considerando-se as diversas editoras e faixas etárias diferentes) imperam nestes últimos quarenta anos e, com tiragens muito altas, atingem um número espantoso de edições e impressões, e, consequentemente, colorem os textos de Shakespeare e os de Lambs, dandoIhes uma forma nova, porém instável, posto que serve para um determinado público e momento histórico específico.

\section{Referências}

AMORIM, Lauro Maia. Tradução e adaptação: Encruzilhadas em Alice no País das Maravilhas, de Lewis Carrol, e Kim, de Rudyard Kipling. UNESP, 2005. 
BASTIN, Georges L. Traducir o adaptar. Universidad Central de Venezuela. Consejo de Desarrollo Científico y Humanístico. Caracas: Facultad de Humanidades y Educación, 1998.

BERTIN, Marilise Rezende. "'Traduções', adaptações, apropriações: reescrituras das peças Hamlet, Romeu e Julietae Otelo de William Shakespeare". São Paulo: USP, FFLCH. 2008.

BIGNOTTO, Cilza Carla. Novas perspectivas sobre as práticas editoriais de Monteiro Lobato. Campinas: UNICAMP, IEL, 2007.

GOTLIB, Nádia Battella. Teoria do conto. In: "Série Princípios 2". São Paulo: Ática, 2006.

LOBATO, Monteiro. A Barca de Gleyre. Quarenta anos de correspondência literária entre Monteiro Lobato e Godofredo Rangel. São Paulo: Companhia Editora Nacional, 1944.

MESQUITA, Samira Nahib de. O enredo. In: "Série Princípios". São Paulo: Ática, 2003.

RICHMOND, Velma Bourgeois. Shakespeare as Children's Literature: Edwardian Retellings in Words and Pictures. USA: Mcfarland, 2004.

WARNER, Marina. "Introduction". In: LAMB, Charles \& Mary. Tales from Shakespeare. England: Penguin Classics, 2007.

WATSON, Kathy. The Devil Kissed Her: the story of Mary Lamb. London: Clays Ltd, 2004.

\section{Bibliografia inicial do conto $A$ tempestade dos Lambs: texto "original", traduções e adaptações brasileiras}

LAMB, Charles \& Mary. "The Tempest". In: Tales from Shakespeare. England: Penguin Classics, 2007.

LAMB, Charles \& Mary. "A tempestade" In: Contos de Shakespeare. Tradução de Januário Leite. 2 volumes. Renascença Portuguesa do Porto. Impressão da Typographia do Annuario do Brasil, RJ, 1921.

LAMB, Charles \& Mary. "A tempestade" In: Contos de Shakespeare. Tradução de Mario Quintana. Ilustrações de J. Fahrion. $2^{a}$ edição. Porto Alegre: Globo, 1943.

LAMB, Charles \& Mary. Contos de Shakespeare. Tradução de Mario Quintana. $7^{a}$ edição. São Paulo: Globo, 2005. 
LAMB, Charles \& Mary. Contos de Shakespeare. Tradução de Octavio Mendes Cajado. Rio de Janeiro: Saraiva (Edições de Ouro), 1965.

LAMB, Charles \& Mary. Contos de Shakespeare. Tradução de Péricles Eugênio da Silva Ramos. Ilustrações de Luís Ventura. São Paulo: Brasiliense, 1959.

LAMB, Charles \& Mary. "A Tempestade". In: Contos de Shakespeare. Recontado por Paulo Mendes Campos. Ilustrações de Lee. Rio de Janeiro: Tecnoprint, 1970.

LAMB, Charles \& Mary. "Romeu e Julieta", "Hamlet", "Macbeth", "Sonho de uma Noite de Verão", "Otelo", "A Fúria Domada", "A Tempestade". In: Contos de Shakespeare. Adaptação de Paulo Mendes Campos. Rio de Janeiro: Ediouro (Edijovem), 2006.

LAMB, Charles \& Mary. "A tempestade". Vol. 1. Tradução de Marcos Bagno. Ilustrações de

LAMB, Charles e Mary. Clássicos a toda hora. "Contos clássicos de Shakespeare": "A tempestade". Ilustrações de Andrés Sandoval. Tradução de Marcos Maffei. São Paulo: Studio Nobel, 2003.

LAMB, Charles \& Mary. "A Tempestade". In: Contos de Shakespeare. Ilustrações de Bernhard Oberdieck e tradução de Sérgio Godinho de Oliveira. Belo Horizonte: Dimensão, 2002.

SHAKESPEARE, William. A tempestade. In: "Série Shakespeare para meninos". No 1. Editor: Monteiro Lobato. São Paulo: Cia. Graphico- Editora. 1925.

SHAKESPEARE, William. : Reencontro. "A tempestade". Adaptação de Sonia Rodrigues. São Paulo: Ática, 2002. 